\title{
AÇÕES DE EDUCAÇÃO AMBIENTAL NA ESCOLA MUNICIPAL DE ENSINO FUNDAMENTAL JOÃO PESSOA - SÃO SEPÉ, RS
}

\author{
Adriana Zafanelli Bolzan ${ }^{1}$, Cibele Rosa Gracioli \\ ${ }^{1}$ Graduada em Licenciatura em Geografia \\ Email: drianazanel@gmail.com
}

\section{RESUMO}

Este trabalho teve como objetivo mostrar através de ações, dentro das normas da Educação Ambiental na Escola Municipal João Pessoa - Tupanci - São Sepé - RS, esclarecendo os alunos da importância da implantação e da preservação da arborização no ambiente escolar. Na metodologia foram utilizados palestras, apresentação de vídeo, coleta de dados, pesquisa qualitativa através de questionário e por fim atividade prática com plantio de mudas. A Educação Ambiental, prevista em Lei Federal no 9.795/99, é uma aliada não só para esclarecer, mas para informar e auxiliar nessa transformação. O palco destas mudanças se inicia na escola, com orientação e esclarecimento das dúvidas, pois quanto mais os alunos aprendem, repassam para seus familiares e serão futuros adultos conscientes e responsáveis por contribuir na preservação da natureza. A partir da preocupação com estas mudanças e suas conseqüências somada à importância da educação ambiental tornam-se possível um crescimento com desenvolvimento e auto-sustentável.

Palavra chave: Natureza, ações, preservação.

\section{INTRODUÇÃO}

Estamos vivendo em tempos de muitos debates e encontros que nos esclarecem a cada dia sobre a importância de preservamos e fazer alguma coisa para ajudar a amenizar tantos problemas que estão surgindo pelo pouco caso dado ao meio ambiente. A escola é o local mais apropriado para dar mais esclarecimento e orientação, pois, quando se começa desde cedo com os alunos de séries iniciais, vai havendo uma maior conscientização deles e interesse, assim passam a incentivar os seus familiares a colocar em prática o que aprenderam e levam para a vida toda também.

Sabe-se que, desde o surgimento das civilizações, o homem vem modificando o meio em que vive, tentando fazer o mesmo que faz com os animais, mas só tem causado gradativamente problema para si próprio no futuro.

Desta forma, a Educação Ambiental tem sido uma das aliadas para mudar gradativamente o modo de ver e agir da sociedade no geral. Uma vez que parte da abordagem de aspectos que são familiares e conhecidos das pessoas, possibilitando, dessa forma, uma aprendizagem significativa, que apresenta assim um grande potencial de se consolidar em mudanças de valores e atitudes, ou seja, na efetivação de uma consciência ambiental no planeta.

Cabe ressaltar a importância deste trabalho por mostrar a cooperação, sensibilidade da comunidade local do interior do município de São Sepé - Tupanci que participa e a parceria entre a Secretaria de Educação do município de São Sepé, Sindicato Rural de São Sepé, SENAR e a escola em questão. 
Trabalhar essa temática dentro dos preceitos da Educação Ambiental na Escola Municipal João Pessoa - Tupanci - São Sepé - RS, esclarecendo os alunos sobre a importância da implantação e da preservação da arborização no ambiente escolar.

- Mostrar a importância de um ambiente arborizado dentro do espaço escola para a comunidade;

- Desenvolver a consciência critica ambiental nos alunos da escola em questão;

- Proporcionar ações voltadas à produção de mudas arbóreas e hortaliças;

- Fomentar a preservação desses espaços e a utilização das plantas produzidas.

\section{REFERENCIAL TEÓRICO}

É através de seus atos que o ser humano tem transformado muitas paisagens, e tem deixado um rastro de destruição que está afetando muitas áreas e provocando problemas sérios para as futuras gerações. Dentro de uma visão mais ampla, o individuo sempre considerou o meio ambiente tudo que o cerca, uma natureza de recursos infinitos onde o mesmo explora sem refletir sobre as consequências que virão a aparecer no futuro, portanto ainda é melhor prevenir do que remediar.

Sendo, portanto a:

Educação Ambiental é um processo que envolve um vigoroso esforço de recuperação de realidades e que garante um compromisso com o futuro. Uma ação entre missionária e utópica destinada a reformular comportamentos humanos e recriar valores perdidos ou jamais alcançados. Trata-se de um novo ideário comportamental, tanto no âmbito individual como coletivo (AB'SABER, 1993, p. 15).

Tendo em vista que segundo as metas estabelecidas na Educação Ambiental, todos os cidadãos devem primeiro ter um conhecimento sobre o assunto para depois refletir na mudança de atitudes, assim se conscientizando do que têm de fazer para mudar seus hábitos e promover uma integração não só individual como coletiva.

Com as hortas escolares implantadas nas instituições de ensino, todos são beneficiados, pois contribui na melhoria da alimentação, proporcionando uma dieta mais nutritiva na merenda escolar. A horta traz uma valorização da preservação do ambiente natural. $O$ papel que o professor desempenha é importante, para desenvolvimento de novos métodos de abordagens e alternativas criativas, para que 0 aluno se integre a ideia de produção e preservação. Considerando que as escolas dispõem de pouco espaço físico na grande maioria, as hortas são feitas através de material reciclável e com materiais disponíveis como garrafas pet, vasos e pneus.

A escola, tendo uma boa arborização, as disciplinas podem ser desenvolvidas no pátio da instituição e novas metodologias de ensino na educação são aplicadas com globalização.

A análise se realizou em uma escola que se situa na zona rural - Escola Municipal de Ensino Fundamental João Pessoa - Tupanci, que pertence ao 5o Distrito do município de São Sepé, na qual a autora é funcionária. Os alunos são filhos de trabalhadores rurais, pequenos produtores que se dedicam à agricultura familiar, proprietários e/ou arrendatários de áreas de produção de arroz ou criação de gado. A situação econômica agrícola se reflete diretamente na escola, gerando a chegada e/ou a saída, frequente de alunos. Alguns estudantes, normalmente aqueles que possuem dificuldade de aprendizagem, ficam na escola sem objetivo de estudar, adolescentes alunos que abandonam os estudos quando completam dezoito anos. 
Assim sendo o que se buscava nesta pesquisa com a aplicação do questionário, era conhecer até que ponto os alunos tinham entendimento e esclarecimento sobre arborização e meio ambiente.

\section{ANÁLISE E DISCUSSÃO DOS RESULTADOS}

A realização das perguntas teve como público alvo os alunos das turmas sessenta e um e setenta e um ambas do Ensino Fundamental num total de 25 alunos. Os primeiros do ciclo de nove anos, com idade de 11 anos e o segundo da série de oito anos, tendo idade de 12 anos. Cada turma em separado recebeu em um primeiro momento o conhecimento para se conscientizar e após a prática.

As respostas foram individuais, mas para efeito de analise e comparação aqui serão reunidas. Assim se tem uma melhor visão das respostas.

Para tanto, a primeira questão consistia no tema deste trabalho: Sua escola é bem arborizada?

Tendo observado que todos os alunos responderam afirmativamente, porém os alunos das duas turmas do sexto ano e sétima série no momento não compreenderam o que significava a palavra "arborização", porque para muitos deles isto era apenas saber se local possuía muitas árvores. Mas o que chamou a atenção foram as respostas da sétima série, sendo acrescentado que as árvores ao redor da escola são lindas e manifestando tristeza devido ao terem sido arrancadas algumas para que pudessem construir uma quadra na instituição. Destacaram que as árvores que ali se encontram proporcionam sombra para eles no verão.

Pode-se perceber com isso que os alunos num todo observam e preocupam-se com as árvores na escola e que estas contribuem para embelezar o ambiente. Segundo informações obtidas junto ao escritório da EMATER do município de São Sepé, de acordo com o Sr.Paulo Secundino Souza Silva, o cinamomo (Melia azedarach L.) não é uma árvore nativa, sendo que as pessoas, por falta de conhecimento, costumam plantar estas mudas em diversas propriedades não só na zona rural em questão, mas na cidade também, deixando de plantar mudas de árvores nativas das localidades que com o passar dos tempos vão sendo extintas e até esquecidas para difundir e dar continuidade ao conhecimento de sua importância junto às novas gerações. Para ele, existem outras espécies nativas que se adaptam bem ao local como a guajivira, uma espécie ornamental nativa e que está sendo utilizada em áreas de degradação ambiental, mas que muitas pessoas não a plantam por ter um crescimento muito lento sendo que ela produz madeira de boa qualidade, cedro (Cedrela fissilis Vell.) também é utilizado para ambientes degradados, Esta espécie é uma aliada importante para o nosso planeta, pois retira o gás dióxido de carbono ou $\mathrm{CO} 2$ da atmosfera, o que é chamado de sequestro de carbono, angico (Parapiptadenia rigida (Benth.) Brenam), ipê-vermelho (Handroanthus serratifolius. (Vahl) S. Grose), ipê-amarelo (Handroanthus albus (Cham.) Mattos), São apenas alguns exemplos de espécies, com suas respectivas importâncias para o meio ambiente, sendo que temos ainda muitas outras. que o mesmo expôs claro que temos muitas outras.

Com relação à segunda questão: As aulas do PIA (Práticas Integradas em Agroecologia) você teria sugestões de atividades?

Os alunos do sexto ano deram suas sugestões para que fossem plantadas mais árvores e flores, outros sim na turma da sétima série estes referiram a coleta de lixo, adquirir mais conhecimento em várias áreas dentro do tema e para sua faixa etária. 
Muito importantes as colocações das duas turmas, os alunos em geral têm uma preocupação em manter o local da escola limpo, pois é ali que os mesmos passam grande parte de suas vidas. Muitos efetivamente participam da coleta seletiva. Querem obter mais conhecimento e demonstram interesse em manter e ampliar o plantio de árvores e flores dando assim um aspecto paisagístico diferenciado a sua escola.

As campanhas publicitárias que são lançadas na mídia visam incentivar o plantio e preservação e a conservação do espaço limpo, Estes alunos estão sim engajados e conscientes da importância de seus atos hoje para terem uma melhor qualidade de vida no futuro.

A terceira questão perguntava: Você gosta destas aulas?

Sendo as respostas positivas ainda foram feitos mais comentários pelos alunos da turma do sexto ano, como: porque tem plantação, trabalho em equipe, aprendem a plantar, aprendem coisas novas, porque falam sobre o meio ambiente, tem trabalho prático, aprendem mais coisas sobre a terra, divertem-se e aprendem, porém aqui houve duas colocações de alunos que não gostam porque têm que trabalhar.

Com as respostas da sétima série foram sim e que ensinam a preservar o meio ambiente, para estes é considerada uma aula diferente e não cansativa.

As atividades escolares desenvolvidas fora da sala de aula despertam e atraem os alunos, pois são algo novo, positivo e estimulante também para as professoras que ali estão engajadas nestas aulas e passam a transmiti-las com mais alegria.

A quarta questão consistia em: O que poderia ser melhorado?

O sexto ano por sua vez concorda com os outros terem mais aulas teóricas e práticas, na turma da sétima série conscientes das suas atitudes, reconhecem que deveriam ser mais comportados, preocupam-se com a limpeza da escola, gostariam de mudanças com mais aulas e assim aprenderiam mais.

Diante destas colocações, fica explicito que eles têm interesse em trabalhar a questão aprender-praticando.

Em relação à quinta questão: Escrever com suas palavras o que você entende por meio ambiente?

Os alunos do sexto ano expressaram-se assim:

- "O meio ambiente é importante para nossa sobrevivência."

- " “É natureza."

- "Tudo que nos rodeia."

- $\quad$ "Deve-se cuidar e não poluir."

- $\quad$ "A gente tem que preservar."

- "Local limpo sem poluição."

- "Que devemos separar o lixo."

Os alunos da sétima série:

- "É o lugar onde vivem seres humanos, plantas e animais."

- " "Meio ambiente é vida com sentimento de amor e esperança."

- " "Meio ambiente onde moramos e para as futuras gerações."

- "Meio ambiente é natureza."

Cada turma coloca um conceito que para eles é verdade e como os mesmos entendem o significado de meio ambiente, sendo que o mesmo é conceituado nos dicionários como: "O meio ambiente, comumente chamado, apenas de ambiente, envolve todas as coisas vivas e não-vivas ocorrendo na Terra, ou em alguma região dela, que afetam os ecossistemas e a vida dos humanos." 
Na pergunta sexta o questionamento era: Qual a importância do meio ambiente para os seres humanos?

O importante para o sexto ano é o verde, a produção de oxigênio e o ar limpo, para nossa sobrevivência e pode respirar sem poluição, água, animais e plantas, ela pega o ar poluído e dá o ar limpo. Para a turma da sétima serie transmite o oxigênio para nossas vidas, produção de oxigênio para nós, a natureza permite nossa existência, retiramos os alimentos para sobreviver, madeira para construir casas e pontes.

O meio ambiente é fundamental para todos e isso fica explicito nas respostas que os alunos como um todo deram, onde cada situação vai depender da outra para poder continuar a sua existência neste planeta.

A questão sétima continha a pergunta: Cite um ou dois prejuízos ao meio ambiente causados pelo homem.

Para a turma do sexto ano os prejuízos são:

- "Aumento da poluição."

- "Desmatamento."

- "Queimadas."

- " "Cortar árvores para fazer lenha."

- " "Poluindo o meio ambiente."

E os alunos da sétima série citam:

- " "Poluição do ar e água."

- "Matança de animais."

- "Queimadas."

- "Contaminação das águas."

Como a realidade de cada um é diferente e sendo o ambiente onde residem o mesmo, muitas respostas tem repetição e semelhança, pois a partir do momento que estes alunos observarem a realidade em outros locais, fora do seu circulo de conhecimento a destruição causada pelo homem e de uma dimensão assustadora.

Em relação a oitava pergunta: Dê uma sugestão de como pode melhorar o convívio do homem com a natureza.

Para o sexto ano seriam:

- "Não derrubar as árvores e sim plantar."

- "Não matar os animais."

- " "Não fazer queimadas no campo."

- "Não jogar lixo em qualquer lugar."

Com relação à contribuição da sétima série temos:

- "Não colocar agrotóxico."

- " "Menos poluição."

- " "Mais preservação."

- "Não desmatar."

- " "Não contaminação da águas."

- "Respeitar a natureza."

Suas contribuições são de vital significação e mostram que estes alunos querem sim um futuro de qualidade e deixar heranças de comprometimento com a valorização da natureza.

Na pergunta nona: Você saberia falar o que irá acontecer com o planeta se as pessoas continuarem causando poluição, desmatamento e jogando lixo na natureza. 


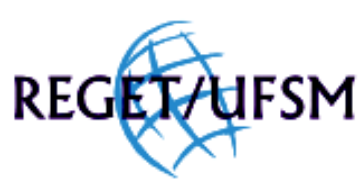

Bolzan \& Gracioli, v(6), no 6, p.1007-1014, 2012.

As respostas dos alunos do sexto ano foram: que o planeta vai acabar vai ficar cheio de lixo, o mundo vai acabar muito quente e se destruir e que quem vai ficar prejudicado é o homem. Com relação à sétima série, estes entendem que o planeta vai acabar sem vida e vai aumentar a camada de ozônio.

Estas respostas refletem que estes alunos sabem da situação que as futuras gerações irão encontrar se não mudarem seus hábitos agora e a escola tem e faz uma diferença neste momento na orientação e fazendo na prática de atividades a continuação destes ensinamentos e mostrando a realidade que devem ser encaradas com preocupação.

Porém na última questão: O que você nota de destruição ou prejuízo que o homem faz na natureza onde você mora?

Para os do sexto ano que na sua compreensão da pergunta responderam: corta os eucaliptos e coloca fogo, derruba árvores para plantar, derrubou e depois plantou novamente. Já para a sétima série percebe que há queimada, desmatamento, poluição do ar e uso de agrotóxico.

As respostas trazem em si verdades que se tem através dos órgãos responsáveis tentando orientarem esta parcela da população rural de não utilizar alguns métodos que venham a prejudicar a natureza e causar mais comprometimento do que já tem. Pois através das queimadas se polui o ar, destrói ainda mais a camada de ozônio e causa o empobrecimento dos solos, queima os nutrientes e para tanto os produtores rurais vão precisar aplicar mais adubos para produzir as suas lavouras. Com relação às derrubadas de árvores notasse uma questão positiva levantada pelos alunos e de significativa importância quando é colocado que derrubam, mas que plantam novamente.

E alguns dias depois foram realizadas aulas práticas com o plantio de mudas no pomar da escola, porém em momentos diferentes, mas com a mesma professora Lúcia Regina Ferreira Pires da disciplina do PIA e a autora do trabalho as turmas sessenta e um e setenta e um. Foi realizado o plantio das árvores cada turma com algumas mudas de cada, sendo Carya illinoensis $K$. (Noz-pecã), Artocarpus heterophyllus Lam. (jaca), Cordia americana (L.) Gottshling \& J.E.Mill. (guajuvira) e Plinia peruviana (Poir) Govaerts (jabuticaba), o plantio de muda de guajuvira foi indicação do responsável pela EMATER - RS Sr. Paulo Secundino Souza Silva.

\section{CONCLUSÕES}

Como forma de poder analisar o entendimento do tema proposto, o questionário levou-os a se questionarem sobre o conhecimento que possuíam. Observou-se que os alunos do sexto ano em partes, alguns devido a sua pouca idade e conhecimento não tinham grandes estímulos e interesses no assunto, refletindo nas atividades da disciplina do PIA.

Entretanto, pôde-se observar que os alunos da sétima série possuíam uma conscientização e reflexão maior dentro de um interesse participativo e cooperativo, não só nas respostas do questionário, como na atividade prática que foi realizada. Este foi um ponto positivo, pois deu ênfase onde e quais assuntos específicos deveriam ser mais aprofundados em cada turma.

O vídeo "A maior flor do mundo" de José Saramago deu um exemplo de grande transformação que o homem causa no ecossistema num todo, trazendo assim uma sensibilização na visão e atitude de uma criança em dar continuidade ao seu desenvolvimento, já que o seu próprio pai (adulto) tinha lhe dado um exemplo negativo de como se modifica o meio ambiente.

De posse destes resultados, é evidente que cada faixa etária tem mais ou menos compreensão e claro precisam ser mais trabalhados determinados assuntos, aprofundando e 


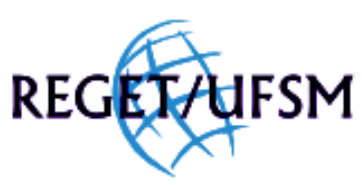

Bolzan \& Gracioli, v(6), no 6, p.1007-1014, 2012.

ressaltando atividades que façam com que estes alunos venham a cooperar e se integrem na proposta lançada. Sendo assim uma boa parcela do grupo de alunos que já se preocupa e conhece os problemas que posteriormente vão afetar seu futuro estes exemplos maravilhosos.

A atitude de manter um comportamento de instrução e orientação traz benefícios para mudanças de hábitos no dia a dia, mesmo aqueles alunos que demonstram desinteresse pela natureza vão aos poucos compreendendo que precisam viver em harmonia e respeito com a arborização em sua escola.

\section{CONSIDERAÇÕES FINAIS}

A escola rural tem levado para a comunidade escolar a educação ambiental sendo difundidas em seu currículo atividades voltadas ao despertar e conscientizar, portanto traz ao meio rural as transformações que o meio ambiente está sofrendo. Pretendendo recuperar com isso atitudes antes totalmente sem importância em um movimento transformador e autosustentável.

Sendo assim, a educação ambiental está inserida nas escolas rurais e traz desafios constantes de mudanças de hábitos e atitudes perante o meio ambiente, para que os alunos associem novos saberes e técnicas para o manuseio das propriedades diversificando seu desenvolvimento.

A legislação ambiental deve ser mais clara em seus objetivos e divulgada para que seja compreendida e respeitada.

Diante das modificações que o meio ambiente vem sofrendo, este está mostrando a cada dia o resultado das atitudes dos seres humanos por não respeitar e conviver em plena harmonia com o mesmo e esta inquietação se expande por todo o planeta.

A cada período de tempo, são realizadas conferências internacionais com a participação de todos os países com o objetivo de analisar e debater soluções para os problemas existentes. Mas isso acaba sendo de pouco entendimento por parte dos países mais desenvolvidos, pois os mesmos acreditam que os menos desenvolvidos devem frear o seu desenvolvimento para evitar consequências ainda mais agravantes para o meio ambiente, porém os mesmos se utilizam disso para continuarem sua trajetória de destruição afetando sim a todos.

Uma atitude simples como levar os alunos para o pátio da escola e thes ensinar como plantar uma árvore surte mais efeito do que simplesmente dizer para que os mesmos cuidem das árvores. Por este motivo devem sim ser incentivados projetos que viabilizam estas atividades desenvolvidas nas escolas, acredita-se que o resultado integração meio ambiente - aluno será com certeza de cuidar, preservar e amar.

\section{REFERÊNCIAS BIBLIOGRÁFICAS}

AB'SABER, A. A Universidade brasileira na (re) construção da Educação ambiental. Educação brasileira, Brasília, v.15, n.31, p. 15 - 16, jul./dez. 1993. 


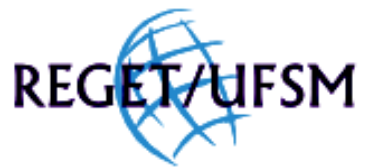

Rev. Elet. em Gestão, Educação e Tecnologia Ambiental

(e-ISSN: 2236-1170)

BIONDI, D. Arborização urbana aplicada à educação ambiental nas escolas. Curitiba : O Autor, 2008.120p.

BOFF, Leonardo. Ecologia e Espiritualidade. IN: TRIGUEIRO, André. Meio Ambiente no Século 21.

Rio de Janeiro: Sextante, 35p. 2003.

unirverde.org/.../EDUCACAO_AMBIENTAL_CONSCIENTIZAR_PARA_SALVAR.pdf Acesso em 5 de abr. 2011.

MACEDO, A.C; Produção de Mudas em Viveiros Florestais Espécies Nativas. Governo do Estado de São Paulo Secretaria de Estado do Meio Ambiente Fundação Florestal. 1993. 